\title{
A PRODUÇÃO MONOGRÁFICA NAS CIÊNCIAS HUMANAS, A RESISTÊNCIA DISCENTE E A POLÍTICA EXTENSIONISTA: UFU $(1985-2015)^{*}$
}

Cícero José Alves Soares Neto

\section{Introdução}

Este capítulo pretende resgatar uma experiência metodológica ocorrida na Universidade Federal de Uberlândia e analisar o que ocorreu, historicamente, na proposta de trabalho da produção monográfica nos cursos das Ciências Humanas. Também, a intenção será compreender a resistência do corpo discente à implantação do sistema de avaliação semestral e anual do trabalho monográfico, no período de 1985-2015. Por fim, a meta final objetiva contextualizar o que foi proposto e o significado histórico, dialeticamente, da propositura metodológica inovadora: expõe-se a estratégia da proposta da produção monográfica nos cursos vinculados às Ciências Humanas, na graduação, e a explicitação da correlação de forças na realidade educacional do ensino superior e, nesta, o confronto das forças atuantes no processo histórico, originalmente.

No segundo momento, o foco interpretativo privilegia, dialeticamente, a negação da proposta de trabalho, oriunda do segmento discente, manifestada na resistência, por intermédio do mecanismo de auto sabotagem. No terceiro momento, o registro analítico se materializa na síntese da proposta de trabalho, ao se instalar a política de extensão universitária na comunidade universitária, por intermédio do Grupo de Estudos Metodológicos (GEM/UFU), como canal de socialização da produção de iniciação científica dos graduandos, por meio dos encontros de iniciação científica, frente ao movimento de resistência discente à produção monográfica.

Teoricamente, esta reflexão afirma que se fundamenta nos paradigmas conceituais desenvolvidos por Paulo Freire (1979), na sua obra clássica, Pedagogia do Oprimido, visando articular o sistema educacional do ensino superior brasileiro com a realidade interpretada, principalmente no

${ }^{*}$ DOI - 10.29388/978-65-86678-84-0-0-f.87-100 
contexto de uma cidade do interior, Uberlândia, de um Estado do Sudeste brasileiro: Minas Gerais. Segundo a sua mensagem paradigmática, o foco central reside entre a palavra, a ação e a reflexão: aonde o ato de criação se faz determinante.

Metodologicamente, esta análise foca numa experiência histórica, procurando desvendar, por intermédio de um estudo caso, um trajeto singular de um processo de trabalho que pretendia, idealisticamente, a implantação de uma proposta de produção monográfica na graduação, direcionada às Ciências Humanas e que, no percurso metodológico, a realidade determinou, dialeticamente, uma linha temática jamais pensada no campo investigativo: "a relação entre as emoções e o câncer". Portanto, diante do registro histórico metodológico da experiência acontecida na realidade do ensino superior, esta reflexão se autoquestiona: como se procedeu na proposta de trabalho extensionista singular na Universidade Federal de Uberlândia?

Estruturalmente, este capítulo se encontra organizado em três capítulos: no primeiro, o foco analítico privilegia a proposta da implantação da produção monográfica na Universidade Federal de Uberlândia, nas Ciências Humanas, no período de 1985-2015. Descreve o contexto da realidade educacional e, neste ambiente acadêmico, a correlação de forças entre duas posturas: a conservadora, que defende o processo educacional vinculado aos fichamentos, e a linha inovadora, que defende a proposta da implantação da monografia como recurso avaliativo no ensino superior. Além disto, aborda como se deu a questão da intervenção do poder burocrático da instituição no conflito metodológico. No segundo capítulo, a proposta busca compreender a resistência do segmento discente diante da proposta da produção monográfica, por intermédio do mecanismo de auto sabotagem. E, para isto, a análise expõe a materialização da resistência discente em articulação externa com o poder público municipal, por intermédio da secretaria de educação, que procura se proteger dos projetos de pesquisa no campo educacional. Entretanto, nas décadas de 1990 e 2010, o Ministério da Educação promove o incentivo aos programas de pós-graduação e a instalação do Trabalho de Conclusão de Curso na graduação das universidades brasileiras. E quais os desdobramentos históricos da intervenção ministerial no ensino superior? No terceiro capítulo, a temática analítica central desta reflexão aborda a criação do Grupo de Estudos Metodológicos (GEM/UFU) e a sua política de extensão como estratégia de socialização dos avanços investigativos materializados 
nas monografias. Para a concretização desta linha extensionista, expõe a parceria institucional com o Núcleo de Estudos da Infância e Adolescência (NEIA), da Escola de Educação Básica (ESEBA), visando promover os encontros de iniciação científica que se tornaram a linha extensionista fundamental de mobilização dos discentes para o investimento nas carreiras universitárias como docentes. Portanto, a proposta interpretativa desta linha de trabalho visa contextualizar o processo histórico do que foi feito e de como se processou a linha educacional no ensino superior brasileiro, por intermédio de uma experiência singular numa instituição mineira: a UFU, nos cursos das Ciências Humanas, por intermédio de uma linha de inovação metodológica: a produção monográfica.

\section{Proposta da produção monográfica nas Ciências Humanas: UFU (1985-2015)}

Este capítulo privilegia a implantação da proposta de trabalho da produção monográfica nas Ciências Humanas, na Universidade Federal de Uberlândia, no período histórico de $1985^{1}-2015^{2}$, privilegiando o confronto metodológico, na realidade educacional do ensino superior, entre os dois estilos de avaliações adotados: o fichamento e a monografia. Diante deste contexto universitário, o foco será a abordagem da intervenção do aparelho burocrático na administração da dualidade metodológica de avaliação semestral e anual.

\subsection{A proposta de trabalho na graduação: a produção monográfica}

Ao ingressar no sistema universitário do ensino superior brasileiro, na Universidade Federal de Uberlândia, na disciplina de Metodologia Científica e afins (Métodos e Técnicas de Pesquisa/MTP, Técnicas de Pesquisa em Economia/TPE), o docente, oriundo do mestrado em Sociologia, na Unicamp, procurou inovar, didaticamente, ao implantar a proposta da produção monográfica, como recurso avaliativo semestral e anual, nos cursos de graduação das Ciências Humanas. Inicialmente, ocorreu uma euforia do segmento discente que foi, gradativamente,

\footnotetext{
${ }^{1}$ Ano de ingresso do docente no ensino superior, por concurso de provas e títulos.

${ }^{2}$ Ano de aposentadoria do docente, após trinta anos e três meses numa única instituição federal.
} 
diminuindo, conforme o grau de dificuldade que o processo de trabalho investigativo apresentava. Por exemplo, os obstáculos que emergiram foram: a escolha da temática monográfica vinculada a uma motivação interna que produziria um estímulo fundamental para enfrentar os desafios oriundos da pesquisa, ora no levantamento bibliográfico, ora na consulta às fontes documentais e ao trabalho de campo ${ }^{3}$. Diante dos obstáculos históricos que apareciam, o desânimo se instalava de forma crescente. A escolha temática da pesquisa, muitas vezes, era determinada por familiares (pai, mãe e irmãos), que sugeriam qual assunto deveria ser investigado. Ao se defrontar com os obstáculos cotidianos, o discente, que não havia definido a escolha da temática, entrava em crise. Daí a instalação do conflito pessoal que se transformava numa relação conflituosa com o docente, pois o orientando queria uma "receita pronta". Deste embate educacional entre o discente e o docente, inicialmente, individual e, posteriormente, social, a resistência do segmento discente tomava corpo e caminhava para o aparelho institucional, ora nas coordenações de curso, ora nas chefias departamentais.

\subsection{Realidade educacional: fichamentos X monografia}

$\mathrm{Na}$ contextualização educacional do ensino universitário, um problema didático toma perfil definido no tronco da disciplina de metodologia científica e suas disciplinas afins, como Métodos e Técnicas de Pesquisa (MTP), principalmente, pois a linha metodológica estava instalada em várias grades curriculares dos cursos de graduação. E qual seria a raiz do conflito metodológico? Na tradição universitária local, a proposta de trabalho dominante se limitava apenas a produção de fichamentos, nos cursos semestrais e anuais. O segmento conservador recebia, com desconfiança, a proposta inovadora. Diante desta correlação de forças, de um lado, a proposta de trabalho vinculada apenas ao recurso didático de fichamento, a linha tradicional que se mantinha numa postura essencialmente conservadora; do outro, uma proposta metodológica inovadora que incomodou os alicerces da proposta antiga estabelecida. Claro que o conflito metodológico foi assumido de forma institucional e, então, tomou contornos burocráticos que se transformaram numa dimensão administrativa, inclusive.

\footnotetext{
${ }^{3} \mathrm{Na}$ época, ainda não existia o CEP, para supervisionar a pesquisa com seres humanos.
} 


\subsection{Correlação de forças: intervenção do poder burocrático}

Nesta correlação de forças desiguais, uma equipe tradicional conservadora que possuía livre trânsito no aparelho burocrático, com influência institucional realmente significativa e que dominava os caminhos da estrutura; e, do outro lado, apenas um docente isolado e inovador (idealista), que rompia com a realidade vigente e sinalizava para uma proposta metodológica da produção monográfica. Este é o horizonte da correlação de forças metodológicas. Elas atuariam no horizonte educacional do ensino superior. Como enfrentar essa correlação de forças desiguais no cenário metodológico? Inicialmente, a postura metodológica tradicional conservadora toma a posição institucional e investe no aparelho burocrático para bloquear a proposta metodológica inovadora. E como isto é feito? Nos colegiados dos cursos e nas chefias departamentais, instala-se uma campanha essencialmente de "exclusão social" da linha metodológica inovadora, que possuía ressonância incomodativa. Um detalhe representativo deste movimento histórico é a passagem do docente por 13 cursos de graduação ${ }^{4}$ nas Ciências Humanas e apenas o Curso de Enfermagem nas Ciências da Saúde. E a correlação de forças se desdobrava de forma crescente, ora acompanhando os trâmites institucionais, ora nas instâncias informais que possuíam um peso realmente significativo e marcante nos contatos sociais. Buscando registrar esse movimento histórico institucional, o autor desta reflexão conseguiu uma informação "oficiosa" (e amigável) de um conselheiro do Centro de Ciências Humanas e Artes (CEHAR), que relatou a seguinte informação oral documental: "percebi uma reação negativa dos membros do Conselho daquele centro (CONCEHAR) à implantação da monografia como requisito obrigatório $e$ indispensável para a conclusão dos diversos cursos ali representados ${ }^{5 \prime \prime}$.

\footnotetext{
${ }^{4}$ Cursos de graduação/UFU: Administração, Artes Plásticas, Ciências Contábeis, Decoração, Design de Interiores, Direito, Economia, Formação Musical, Letras, Geografia, Psicologia, Pedagogia e Teatro.

${ }^{5}$ Grato pela coragem da informação dada de forma corajosa e confidencial. Entretanto, a informação foi documentada por um registro escrito. Contudo, preserva-se o anonimato.
} 


\section{A Resistência do segmento discente: mecanismo de auto sabotagem ${ }^{6}$}

Este capítulo privilegia abordar a resistência do segmento discente, focando no mecanismo de auto sabotagem como estratégia pessoal de enfrentar o desafio monográfico. Além disto, sinaliza para a aliança externa, com a participação do poder municipal. E, também, destaca a política educacional do Ministério da Educação que implanta a monografia nos cursos de graduação, quando do recredenciamento dos cursos de graduação nas universidades brasileiras.

\subsection{O mecanismo de auto sabotagem: estratégia de defesa pessoal}

No desenvolvimento do movimento de resistência manifestado pelo segmento discente, durante todo esse envolvimento cotidiano no ensino superior, o metodólogo percebeu um recurso fundamental de participação discente significativa que chamou a atenção do docente: o mecanismo de auto sabotagem diante do desafio da produção monográfica. Historicamente, o metodólogo construía um vínculo pessoal e confidencial, apesar da resistência educacional, que permitiu construir a percepção de como ocorria a estratégia, inconscientemente, de se contrapor a proposta de trabalho acadêmico, com recursos de bloqueios por intermédio do mecanismo fundamental: "a auto sabotagem". Percebiase, sutilmente, que havia uma cultura de resistir à proposta de trabalho da produção monográfica, construindo subterfúgios que justificassem a fuga ou o bloqueio do desafio do trabalho acadêmico. Na cultura de resistência de auto sabotagem, inúmeros recursos são ativados, cotidianamente, como estratégia de fugir da meta acadêmica: a produção monografia. Apesar de não ter ocorrido na instituição educacional federal, na qual o docente estava lotado, existe um registro histórico nacional de auto sabotagem que serve de exemplo clássico do fenômeno na realidade universitária brasileira: "a universitária S. P. F. C.", de 22 anos, confessou à Polícia Civil de Belém que forjou o próprio sequestro, por não ter terminado o trabalho de

\footnotetext{
${ }^{6}$ Alerta-se, desde já, que, em todo o texto, evita-se a identificação pessoal ou institucional, para que se evite problema de ordem pessoal.

${ }^{7}$ Preserva-se o anonimato da discente universitária, de forma ética.
} 
conclusão de curso (TCC) a tempo de apresentar" ${ }^{\prime \prime}$. Nesta lógica, os recursos usados transcendem à imaginação do que se pode valer o discente para contornar a produção monográfica. No amadurecimento do metodólogo, a percepção evolutiva do problema do mecanismo de auto sabotagem toma corpo e formata o olhar sutil do docente, para identificar, na atualidade, a materialização do mecanismo de auto sabotagem na clínica de fisioterapia, por intermédio de recursos ortopédicos, para fugir de desafios que a realidade prepara para cada um de nós. Claro que isto acontece de forma inconsciente. Percebe-se como aqueles corpos bloqueados traduzem os desafios da vida, pelo mecanismo inconsciente da sabotagem contra si mesmo. Se ocorrer uma investigação daquela limitação física, com a história pessoal, pode-se descobrir, no laboratório fisioterápico ${ }^{9}$, a origem do problema somático. Portanto, aquele singular registro somático deve traduzir, num olhar mais criterioso, a materialização da sabotagem no próprio corpo que registra o mecanismo singular da resistência pessoal, pois não se pode colocar a culpa numa pessoa externa. Não existe um terceiro personagem, como fonte de transferência, do problema vivenciado pessoalmente.

\subsection{Aliança externa: intervenção do poder municipal}

A correlação de forças existe com uma configuração real do confronto entre o docente e o segmento discente, intermediado pelo processo de trabalho da produção monográfica. A evolução do problema toma contornos de crescimento e a próxima etapa terá a participação de um novo agente político: o poder público municipal, intermediado pela secretaria de educação. Qual foi a justificativa oficiosa que circulou no contexto acadêmico para a participação do poder público municipal? E como isto aconteceu? No ano de 1998, uma turma de um determinado Curso $^{10}$ das Ciências Humanas apresentou um abaixo-assinado, que questionava a proposta de trabalho do docente, materializando a resistência do discente, de forma documental. Nas "fontes oficiosas" comunicativas do Campus Santa Mônica, circulava a informação de que o verdadeiro objetivo da produção monográfica seria a pretensão de produzir denúncias contra o sistema educacional municipal. Somente o docente não

\footnotetext{
${ }^{8} \mathrm{https}$ //www.terra.com.br/noticias/brasil/policia/pa-por-nao-entregar-tcc-estudante-forjao-proprio-sequestro,eb5fac68281da310VgnCLD200000bbcceb0aRCRD.html

${ }^{9}$ Sugestão de uma linha de investigação empírica, após passar pelo CEP, claro.

${ }^{10}$ Continua a linha sem identificação nominal do curso.
} 
tinha conhecimento da estratégia de denúncia, vinculada à produção monográfica. E como o metodólogo enfrentou o problema da resistência discente desta específica turma? Simplesmente, o docente reconheceu a solicitação dos discentes, abrindo mão da proposta construída e se desvinculou de sete projetos ligados a proposta da política de iniciação científica: Educador do Século XXI, Empresário Educacional do Século XXI, Iniciação Científica, Cursos de Extensão, Política de Eventos, Participação em Congressos Nacionais e Produção Científica. Contudo, nada disto mobilizou o metodólogo para desistir, apenas da flexibilidade, para recuar no momento histórico crítico, diante de uma postura conservadora forte, politicamente articulada.

\subsection{Ministério da Educação (MEC): monografia na graduação (1990)}

Na década de 1990, o Ministério da Educação (MEC), por meio de uma política ministerial direcionada ao sistema de ensino superior brasileiro, incentivou a disseminação dos programas de pós-graduação nas universidades brasileiras, os mestrados, nas unidades departamentais. $\mathrm{Na}$ década de 2010, a política ministerial privilegiou a implantação do Trabalho de Conclusão de Cursos na graduação. Na realidade, a diretriz inseriu uma tipologia de opções de trabalhos, sob o manto do TCC: memorial crítico, artigo científico e a monografia. Diante da proposta oriunda do poder central, no caso, da fonte ministerial, e, em função da convivência cotidiana, no interior institucional da comunidade universitária, percebia-se que a resistência havia se instalado, também, no corpo docente. Assim, a diretriz ministerial se impunha, institucionalmente, pois se originava da esfera federal. E o que significou essa política ministerial? Apesar de não existirem fontes oficiais publicadas, como estudo de caso institucional, percebe-se, por conhecimento cotidiano e via participação nos colegiados de cursos e nos conselhos departamentais, que o nível de adoecimento no segmento docente toma um nível alarmante, principalmente, por problema de saúde oncológico, além de outras patologias. Algumas unidades institucionais (departamentos) registram óbitos por essa patologia no segmento docente, num grau elevadíssimo. Na realidade contemporânea, dois outros registros temáticos merecem destaque para o desdobramento da reflexão: a depressão e o suicídio, no segmento discente. Além de atingir os segmentos docente e administrativo, também. Inclusive, como registro ilustrativo e histórico, a Instituição Casa das Cenas debateu a temática, no 
Campus Santa Mônica/UFU, em novembro e dezembro de 2018, com o título: "Depressão e Suicídio: cuidados pelo olhar psicodramático 11". Para registrar a problemática, uma determinada unidade acadêmica ${ }^{12}$ registrou duas tentativas e dois suicídios, apenas num período anual, recentemente. Portanto, o problema mencionado toma uma dimensão de contornos preocupantes na comunidade universitária da UFU e nos dois segmentos: docente e discente. Qual seria a origem do problema? Como cada segmento (docente e discente) está reagindo ao contexto da pressão social na realidade atual ? $^{13}$

\section{Grupo de Estudos Metodológicos (GEM/UFU): política extensionista}

Neste terceiro capítulo, a intenção analítica será privilegiar a política de extensão do Grupo de Estudos Metodológicos (GEM/UFU), como estratégia educacional de fazer frente ao movimento de resistência à proposta da produção monográfica. Nesta correlação de forças, ocorreu a parceria institucional com a Escola de Educação Básica, por intermédio do Núcleo de Estudos da Infância e Adolescência (NEIA), para articular o avanço institucional desta linha de trabalho.

\subsection{Encontros de Iniciação Científica: início da socialização}

A estratégia de trabalho da proposta da produção monográfica se estruturava em três vias: o ensino ${ }^{14}$, a pesquisa ${ }^{15}$ e a extensão. Nesta reflexão, o foco prioriza sistematizar, apenas, a política de extensão, desenvolvida por esta linha de trabalho. Para isto, a visão extensionista apresenta o planejamento estratégico em três momentos: no curto, no médio e no longo prazo. No primeiro, no curto prazo, a meta é expor as monografias produzidas pelos discentes veteranos aos alunos ingressantes do vestibular, periodicamente. No segundo, no médio prazo, a meta extensionista seria expor a produção monográfica na comunidade

\footnotetext{
${ }^{11}$ casadascenas@hotmail.com

${ }^{12}$ Curso das Ciências Humanas.

${ }^{13}$ Uma linha de investigação bastante significativa na atualidade.

${ }^{14} \mathrm{~A}$ abordagem da temática do ensino será abordada numa outra reflexão, brevemente.

${ }^{15}$ A reflexão conceitual acerca da temática da pesquisa também será discutida num próximo trabalho.
} 
universitária da UFU, nos seus eventos internos, e nos encontros externos, regionalmente. $E$, no longo prazo, a política de extensão provocava a participação dos discentes nos congressos de nível nacional, como a SBPC. A partir do exposto do planejamento estratégico metodológico, no primeiro semestre de implantação da proposta de trabalho, a política de extensão foi instalada no ano de 1985, e a fonte jornalística do Correio de Uberlândia registrou o momento histórico inovador com a manchete: "Debates movimentam alunos de 3 cursos na UFU"16. E a reportagem comunica que os alunos dos Cursos de Artes Plásticas, Decoração e Formação Musical apresentariam os seus trabalhos desenvolvidos na disciplina de Métodos e Técnicas de Pesquisa II. A configuração da proposta de trabalho vai se delineando nos semestres seguintes e, então, ocorrem os Encontros de Iniciação Científica dos discentes para os alunos ingressantes. Num evento posterior, no ano de 2010, o texto de apresentação do evento afirma que "a filosofia desta proposta de trabalho metodológica repousa fundamentalmente na autonomia e independência preconizada por Paulo Freire". E reafirma o texto que "o estímulo a aquisição do processo de criatividade que o sistema educacional vigente tenta implantar"17. E quem levaria a proposta de trabalho, por intermédio da política de extensão? Essa função extensionista ficou reservada ao GEM/UFU, Grupo de Estudos Metodológicos, que foi criado com o objetivo de articular e mobilizar a proposta de trabalho da produção monográfica, comandando as metas previstas nas reuniões do GEM. E tinha como objetivo, fundamental, confrontar-se ao movimento de resistência do segmento discente. E a dimensão extensionista da proposta de trabalho do GEM/UFU teve, no XIV Encontro Itinerante de Iniciação Científica, ocorrido em 05 de abril de 2003, numa Instituição local renomada, o Colégio Nacional, um registro significativo: sete comunicações orais e onze painéis. $O$ encontro congregou discentes de seis cursos das Ciências Humanas, apenas. Pelo nível de maturidade e amadurecimento dos envolvidos com a proposta de socialização das monografias, o evento representou o ápice da linha de trabalho que foi alcançada a meta, historicamente. Contudo, a dimensão qualitativa dos eventos em si foi superada pelos Encontros de Iniciação Científica, na articulação com a parceria com o NEIA/ESEBA. Portanto, a proposta de trabalho, idealisticamente pensada, teve a dimensão

\footnotetext{
${ }^{16}$ Correio de Uberlândia, Uberlândia, 25 de junho de 1985, p. 12.

${ }^{17}$ III Encontro de Iniciação Científica do Curso de Filosofia da UFU, calourada de 2010.
} 
determinante da realidade como pressuposto para a materialização da linha de trabalho, dialeticamente.

\subsection{Parceria institucional: Núcleo de Estudos da Infância e Adolescência (NEIA)}

A proposta de trabalho extensionista procurou sair do espaço interno e buscou alianças com grupos de participação socializante na comunidade universitária da UFU. Inicialmente, ocorreu a parceria com o NEIA (Núcleo de Estudos da Infância e Adolescência), da Escola de Educação Básica (ESEBA), instituição também vinculada a UFU. O intercâmbio entre os dois grupos, o GEM e o NEIA, se refletiu numa política de reuniões planejadas, nas quais os trabalhos produzidos eram socializados e interativamente dialogados pelos participantes da produção científica dos discentes e dos docentes vinculados a ESEBA. No convívio interativo, o grau de amadurecimento se refletia na qualidade das perguntas, pois as análises críticas contribuíam para os avanços significativos das pesquisas individuais expostas. No V Intercâmbio de Pesquisa Científica, GEM e NEIA, ocorrido em 23 de novembro de 2003, a produção socializada refletia o que se produzia nas duas unidades institucionais e provocava um estímulo na comunidade universitária, pela qualidade das comunicações orais produzidas.

\subsection{Formação universitária: carreiras acadêmicas}

O GEM/UFU promoveu o "10 Encontro do GEM", no ano de 2013, no qual os discentes originários dos eventos da política de iniciação científica e participantes da proposta de trabalho da produção monográfica, desde o início, expuseram as suas dissertações de mestrado e as suas teses de doutorado, socializando as suas pesquisas para a comunidade universitária da UFU. No evento, ocorreu uma materialização histórica da proposta de trabalho de um processo de trabalho, originalmente idealista, mas que a realidade do ensino superior reformatou, de forma dialética. Além disto, a confirmação desta linha de trabalho se consolidou, pois, quase todos os participantes eram professores universitários com doutorado ou mestrado, produzindo reflexões significativas que se originavam da proposta inicial: investir na "motivação interna". 


\section{Conclusão $^{18}$}

Esta experiência metodológica relatada contribuiu, significativamente, para despertar o metodólogo para a temática investigativa sobre a qual se debruça na atualidade: "a relação entre as emoções $e$ o câncer". A problemática do mecanismo de auto sabotagem contribuiu para o desenvolvimento do olhar do docente para o vínculo emocional com a patologia, sob o prisma dos registros memorialistas dos que foram acometidos do problema de saúde oncológico. Nos registros autobiográficos dos autores memorialistas adoecidos, um fato fundamental ganha destaque no relato estritamente pessoal: $o$ processo de interiorização do biógrafo memorialista. Nesse depoimento essencialmente emocional, o testemunhante (memorialista) aborda a questão do mecanismo de auto sabotagem de forma sutil, como um recurso de compreender a sua patologia. Assim, existe um depoimento da história estritamente pessoal com o problema vivenciado com a patologia. Diante deste ganho temático, a relação emocional com a patologia, a perspectiva do metodólogo foi reconstruir a evolução da linha de trabalho, inclusive, esta reflexão se transforma num passo significativo de compreender o processo histórico a partir do foco central: o mecanismo de auto sabotagem. Entretanto, o sistema de interiorização ainda é desafiante ao docente pela complexidade temática vivenciada, incrustada na Sociologia das Emoções e na Sociologia do Corpo. Nos eventos Latino Americanos, e, também, em Portugal e na Espanha, a temática tem tomado dimensão bastante expressiva nos Grupos Temáticos. Portanto, a conquista do que se investiga na atualidade tem ligação com a resistência do segmento discente: o mecanismo de auto sabotagem, com certeza.

Assim, o processo comunicativo do conflito da resistência do segmento discente se manifesta de forma sutil, por intermédio do mecanismo de auto sabotagem, para o olhar do metodólogo, que conquistou uma nova temática realmente representativa do problema pessoal e social, também. Isto posto, a proposta de inovação metodológica, a produção monográfica na graduação, originalmente idealista, ao interagir com o contexto universitário, principalmente o segmento discente, dialoga com o mecanismo de resistência do segmento discente, e, então, se refaz,

${ }^{18}$ Como todo o texto registrou, privilegiou-se a identidade anônima, pois a realidade comunitária é bastante conservadora, no caso, Uberlândia, e, por extensão, a instituição federal. Então, por cuidado diplomático, evita-se identificar algo, para não incomodar. 
dialeticamente, e percebe uma nova frente de investigação materializada na relação entre as emoções e o ato de adoecer, por intermédio do câncer, em particular. Este desdobramento evolutivo da percepção do olhar inicial do mecanismo de auto sabotagem, manifestado pelo discente, como reação de resistência à produção monográfica, determina um novo campo de investigação ao metodólogo. Neste desafio estritamente pessoal, não custa questionar, de forma ampliada, aos vários doutores e professores universitários oriundos da proposta metodológica, qual a leitura crítica da linha de trabalho vivenciada, historicamente? Ou seja, qual a sua percepção analítica da formação acadêmica na trajetória?

\section{Referências}

BRANDEN, Nathaniel. A auto estima e os seus seis pilares. 3a ed. São Paulo: Saraiva, 1997.

FREIRE, Paulo. Pedagogia do Oprimido. 6a ed. Rio de Janeiro: Paz e Terra, 1978.

FREIRE, Paulo. Pedagogia da autonomia: saberes necessários à prática educativa. 16a ed. São Paulo: Paz e Terra, 2000.

HERMES, Patrícia; ROSNER, S. O Ciclo da auto sabotagem: por que repetimos atitudes que destroem nossos relacionamentos e nos fazem sofrer. Rio de Janeiro: Best Seller, 2009. 